\title{
Os tecidos vegetais têm três dimensões
}

\author{
GREGÓRIO CECCANTINI ${ }^{1}$
}

A pergunta central que se faz de início é: - Será que o ensino da Anatomia Vegetal está sendo bem sucedido? Ao final de qualquer curso de anatomia corrigem-se as provas, aprovam-se os alunos, mas não se pode ter certeza de que o conteúdo foi bem aprendido, já que o contato entre mestres e alunos após as avaliações é raro.

$\mathrm{E}$ as habilidades dos alunos foram devidamente lapidadas? Que habilidades em um curso de morfologia vegetal devem ser aprimoradas? Podem-se citar muitas, mas uma em especial me parece fundamental, e essa, aparentemente, não tem sido muito bem explorada: a compreensão tridimensional das estruturas. Essa habilidade é essencial, pois será usada adiante em outras disciplinas das Ciências Biológicas, nas atividades de docência ou pesquisa do futuro licenciado ou bacharel. Percebo que, em alguns cursos de Anatomia Vegetal, a ênfase tem sido a memorização de nomes de estruturas, em detrimento da compreensão espacial das mesmas, o que frustra os alunos e pouco contribui para seu conhecimento - é um aumento de gordura (que pode ser perdido depois), quando seria mais útil um aumento no esqueleto. Assim, os objetivos deste texto são o de destacar algumas dificuldades no ensino de Anatomia Vegetal, propor alternativas e compartilhar experiências de um dos projetos desenvolvidos.

Na década de 80, o Dr. Douglas Zago (professor de histologia e embriologia animal no ICB-USP) dizia, em suas aulas, que "o histólogo, por definição, é um cientista infeliz, pois tenta entender em duas dimensões um mundo que tem três". Apesar de avanços tecnológicos recentes, como a microscopia confocal e os programas de computador para reconstrução tridimensional, eles ainda não são amplamente difundidos nos laboratórios e, em geral, estão distantes da sala de aula. Assim, a afirmação acima ainda é bastante verdadeira. Por esse motivo, no ensino de histologia

1. Universidade de São Paulo, Departamento de Botânica, Caixa Postal 11461, 05422-970 São Paulo, SP, Brasil. animal e anatomia vegetal a integração tridimensional é tão importante e complicada. Para que ela ocorra de forma adequada, deve-se exercitar a capacidade de abstração, tendo como base imagens bidimensionais, como desenhos de cortes ou fotomicrografias.

De forma a suprir essa dificuldade inerente às ciências histológicas, as representações gráficas didáticas têm evoluído muito. Se observarmos os principais livros de Botânica e Anatomia Vegetal nas últimas décadas (Eames \& McDaniels 1947; Esau 1960; Fahn 1967; Cutter 1978a, 1978b; Mauseth 1988, 1995; Raven et al. 1978, 1996, 2001), verificamos que o número de esquemas tridimensionais aumentou, bem como sua complexidade, o que vem facilitando muito a compreensão das estruturas por parte dos alunos.

Apesar disso, muitas das respostas apresentadas em provas e trabalhos demonstram que a compreensão das estruturas espacialmente deixa, ainda, a desejar. Um exemplo desse problema é a quantia de vezes que os alunos descrevem as células como sendo "círculos" e "retângulos", em lugar de esferas ou cilindros e prismas. Por isso, métodos e recursos que auxiliem nessa tarefa são sempre bem-vindos.

Um recurso, que muito pode ajudar, é o uso de modelos didáticos tridimensionais. Diversas empresas comercializam, no Brasil e no exterior, modelos feitos de diversos tipos e materiais (resina, gesso, polímeros), mas esses costumam ser caros, de disponibilidade e diversidade limitadas e, freqüentemente, contém erros. Considerando essas limitações, uma alternativa interessante é o uso dos modelos didáticos como parte do método de ensino. Se a compra de modelos sofisticados não está ao alcance de todas as escolas, a confecção de modelos com certeza está, pois envolve apenas determinação e criatividade, duas faculdades importantes para o cientista-professor de ciências biológicas. Com o desenvolvimento de modelos, estimula-se o aluno a refletir sobre as estruturas de forma a se aprofundar na sua compreensão tridimensional. A construção de modelos pelos alunos, usando materiais simples (cartolina, acetato, isopor), como massas plásticas (massa de modelar, massa de vidraceiro, porcelana fria), gesso ou materiais reciclados (PET, 
plástico bolha, embalagens) é muito empregada no ensino fundamental e médio, mas lamentavelmente, pouco aplicada no ensino superior.

No Brasil uma entusiasta pioneira no uso da construção de modelos para o ensino de Anatomia Vegetal foi Dra Marilene Braga (UFMG). Também na UFMG, a convivência enriquecedora desta, com a Dra Rosymary Isaias, resultou em inovadora investida no ensino de Botânica para deficientes visuais. Por entusiasmo em relação ao trabalho da primeira, fabriquei alguns modelos em 1997 e implantei a construção de modelos tridimensionais como parte do método de ensino e avaliação de Botânica Estrutural na Universidade Federal do Paraná, como o que segue anexo, com bastante sucesso. Houve retorno em motivação dos alunos, em resultados das avaliações, bem como pela constituição de uma coleção de modelos de ótima qualidade.

Vale a pena destacar que os modelos também podem auxiliar a sanar deficiências nos recursos didáticos, cada vez mais freqüentes na Universidade brasileira. Podem complementar os laminários deficientes ou suprir a indisponibilidade de equipamentos, como micrótomos de deslize ou microscópios eletrônicos de varredura. O modelo aqui apresentado, por exemplo, foi brilhantemente desenhado por Luciana Gussella, com o uso de lâminas histológicas de madeira de jatobá (Hymenaea courbaril L.), que não estão disponíveis em boa parte das coleções didáticas que visitei, e se estão, não em número suficiente.

Um problema que vem prejudicando o ensino é o envelhecimento ou a má qualidade dos microscópios. Em muitas escolas a observação não é em nada favorecida pelos aparelhos, que vêm diminuindo em número e em qualidade. Em alguns locais o número de microscópios, já insuficiente para trabalhos em duplas, não permite a observação de estruturas muito pequenas, como pontoações areoladas que variam de 1-10 $\mu \mathrm{m}$, áreas crivadas ou estrias de Caspary, já difíceis de compreender com boas condições de microscopia.

Para concluir, quero manifestar meu entusiasmo com relação ao uso de modelos didáticos tridimensionais, tanto como recurso didático, como enquanto método de avaliação e construção de habilidades estruturadoras.
É impressionante como, agregando um aspecto lúdico e criativo, podemos transformar uma aula de anatomia vegetal numa atividade divertida e agradável para todos. É difícil explicar as razões pelas quais fomos treinados para rejeitar a criação e a diversão no ensino, mas há boas teses acadêmicas relacionando isso ao fracasso escolar, à repressão e à evasão dos cursos.

Boa parte do que fazemos em nossa atividade profissional de biólogo nos parece divertida (atividades de laboratório, trabalho de campo). Por outro lado, alguns dos atributos mais importantes para o profissional biólogo (pesquisador ou professor no Brasil) são improviso e criatividade para suplantar as limitações materiais. Por esses motivos, conclamo os colegas professores a usarem o modelo aqui apresentado, e verificar como é possível agregar uma faceta lúdica numa aula de anatomia do xilema secundário, que pode nos remeter aos tempos em que brincávamos com o "Recorte \& Brinque" das embalagens de cereais ou com a "Revista Recreio". De bônus, os alunos ainda levam seu modelo para casa, difundem aquele objeto curioso entre seus familiares e não têm a desculpa de não ter tido livro para estudar, por exemplo, os três planos de organização da madeira.

EAMES, A.J. \& MCDANIELS, L.H. 1947. An introduction to plant anatomy. McGraw-Hill Book Company, New York.

ESAU, K. 1960. Anatomy of seed plants. John Wiley \& Sons, New York.

FAHN, A. 1967. Plant anatomy. Pergamon Press, Oxford.

MAUSETH, J.D. 1988. Plant anatomy. The Benjamin/ Cummings Publishing Company, Menlo Park.

MAUSETH, J.D. 1995. Botany: An introduction to plant biology. Saunders College Publishing, Philadelphia.

CUTTER, E.G. 1978a. Plant anatomy - Part I: cells and tissues, $2^{\text {nd }}$ ed. Edward Arnold, London.

CUTTER, E.G. 1978b. Plant anatomy: experiment and interpretation - Part II: organs, $2^{\text {nd }}$ ed. Edward Arnold, London.

RAVEN, P.H., EVERT, R.F. \& CURTIS, H. 1978. Biologia vegetal. Guanabara Dois S.A., Rio de Janeiro.

RAVEN, P.H., EVERT, R.F. \& EICHORN, S.E. 1996. Biologia vegetal. Guanabara-Koogan, Rio de Janeiro.

RAVEN, P.H., EVERT, R.F. \& EICHORN, S.E. 2001. Biologia vegetal. Guanabara-Koogan, Rio de Janeiro. 


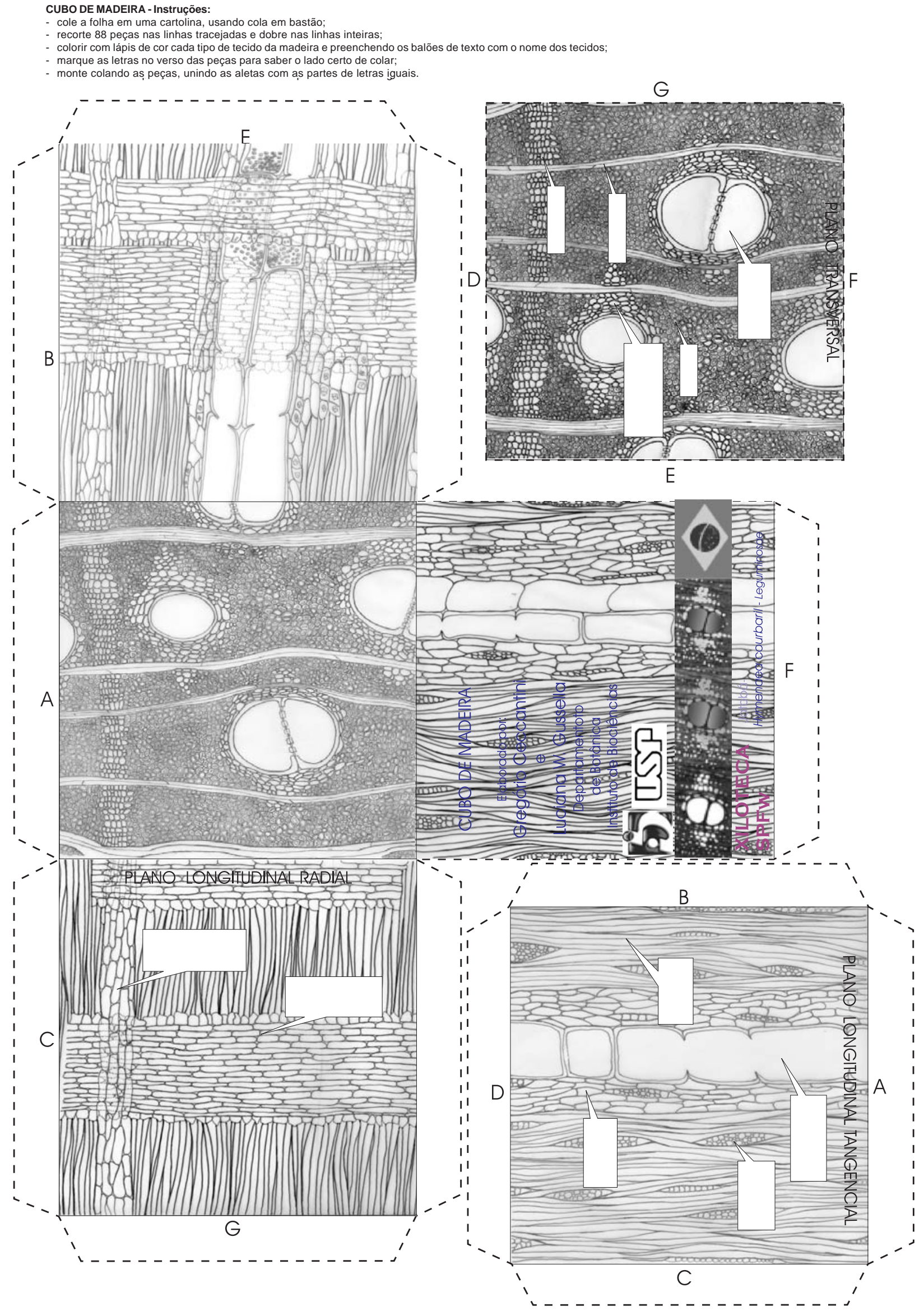

